likened to the paralysis which in one always, and in the other generally, accompanies them, but in "precocious dementia" this is rather an ataxy of the mind, There is inco-ordination, not paralysis. Therefore dementia is a very faulty term to use here. The qualifying adjective "precocious" is also to be deprecated. To call anything precocious merely because it occurs in early life is a perversion of terms, for "precocious " implies too early arrival at an inevitable end. Neither are these mere verbal quibbles, for the epithets beg the question. It is admitted, however, that Dementia Prxcox is not absolutely incurable, and we are even advised, as Wernicke has pointed out, to treat cases early so as to give them the best chance of recovery. It is then wrong to dub them by a name which encourages despair.

Dr. DAvid ORR and Dr. W. G. Rows showed, with the aid of a lantern, a series of microscopical preparations to illustrate the course of "degenerative lesions of the posterior columns of the cord in general paralytics," and particularly to show the "point of origin of tabes dorsalis." By complementary methods of staining, and the selection of very early cases of the disease it was possible to show that the point of special vulnerability to the disease corresponded with the point where suddenly, just before their entry into the spinal cord, the posterior root-fibres lose their protective sheath. It was suggested that the disease was due to a special liability to toxic action which acted first at the most vulnerable point. The research was not yet complete, but as far as it went the evidence was very convincing.

Dr. A. T. Schofirld read a paper on the "Cure of Quackery," the essential point of which was that for the most part the quack utilised the powers which the mind exerts in an obscure way over the bodily functions in the cure of disease. His plea was that these natural powers should be studied, their laws investigated, their uses and actions incorporated in the science of medicine, taught in the schools and practised in the consulting-room, and thus the ground would be cut from under the feet of the quack.

Dr. PASMORE read a paper on "How to make a Family History." He pointed out that the collection of the facts as to the mental and other conditions in antecedent and collateral relatives was a complex matter, and one very difficult to carry out completely and rapidly unless some definite and simple scheme is adopted. He passed round a diagram of the scheme he had adopted in his own practice which enabled him to secure full data for three generations back in any case with ease and completeness. Further back than this the information obtained would not be worth securing. The general adoption of some such scheme would secure a desirable uniformity, and the President said he would bring the matter before the Statistical Committee of the Medico-Psychological Association.

\title{
THE HORTON ASYLUM SCANDAL.
}

At the Surrey Assizes, held at Guildford yesterday, before Mr. Justice Darling, Thomas Wiles, twenty-three, carman, Maurice Clark, thirty-three, butcher, Charles Edward Morant, clerk, and Alexander James Ross, twenty-seven, clerk, were again brought up on indictments connected with the Horton Asylum scandal. The prisoners were indicted for conspiring together to steal a quantity of groceries and other goods, the property of the Asylums Committee of the London County Council, at Horton Asylum, near Epsom, between April 4th, 1903, and March 16th, 1904. They were also indicted for specific cases of theft. Altogether there were seventy-one counts in the indictment.

Mr. H. F. Dickens, K.C., Mr. George Elliott, and Mr. Cecil Whiteley prosecuted for the London County Council; Mr. Huntley Jenkins and Mr. Curtis Bennett represented Clark; Mr. Bridgwater appeared for Morant; Mr. H. Brandon for Wiles and Ross. A watching brief on behalf of a firm of contractors was held by Mr. Heber Hart.

At the outset there was an argument as to whether the statement made by Morant at the police-court should be put in, after which-

The Judge said he should tell the jury that this was evidence against Morant to 
prove Morant guilty of conspiracy. It would be for the jury to say with whom Morant had conspired.

Morant's statement was read. He said that a system of book-keeping at the asylum was largely responsible for the present state of affairs. Not one of the asylum's sets of store books would stand the test to which those books had been subjected by the firm of accountants. The books had been badly kept before he went to the asylum, and he had to make many alterations in order to get them right. They never liked to have a lot of over-stock, and it was usual to get rid of the over-stock. He had seen barrels of limejuice and vinegar poured down the drains, and that was considered nothing. Seeing such a waste, he thought there was no harm in taking some of the things for himself. He had seen a ton of granulated sugar melted down in that way. Morant also alleged that some officers of the asylum had been in receipt of sums of money from contractors.

Evidence having been given as to the manipulation of the books, the case for the prosecution was closed.

Counsel for the defence offered no evidence.

Mr. Dickens, K.C., in addressing the Court for the prosecution, said he had put in Morant's statement as evidence against Morant, but he did not ask the jury to believe the whole of it. He characterised Morant's statement as to sugar and fat having been poured down the drains as "absolute moonshine." The story was invented to cover his own misdeeds. With regard to the evidence of the witness Norris, he pointed out that it was corroborated in every detail with one exception. Mr. Brandon, on behalf of Wiles, said Norris was undoubtedly a clever man, but he was going to ask the jury not to place absolute reliance on what Norris had said.

Mr. Jenkins submitted that there was no evidence of conspiracy. If any offences had been committed they had been committed by men acting independently. He was not the instrument of anybody, and it was shown that he moved goods to many places and to other asylums.

Mr. Bridgewater, for Morant, also contended that there was no conspiracy.

The judge, in summing up, told the jury that they must treat Norris's evidence carefully. With reference to the suggestion that his evidence was uncorroborated, there was corroboration on some points, because it had been proved that goods had been removed from the asylum. No explanation had been vouchsafed. He invited the jury to express an opinion with reference to the conduct of the asylum. It would assist him in passing sentence, and might also assist the County Council.

The jury found all the prisoners guilty of conspiracy. They recommended Wiles to mercy. They added that in their opinion the Horton Asylum had been grossly mismanaged, and that the conduct of those responsible for its administration ought to be seriously inquired into.

In passing sentence the judge said he thought the Horton Asylum was grossly mismanaged, and that enabled him to take a lenient view of the conduct of the prisoners. There was no proper control or supervision. The man in charge received only a salary of 6200 , rising to $\$ 250$. The rest of the men, if they once became dishonest and could get one accomplice, could make away with the stores as they had done. Norris had stated that there were twenty-six people included in this malversation. It would not surprise him to know that this was so. There were already four persons in the dock, and they had heard that others had been discharged from employment. It might be that the whole management of the asylum was criminal from top to bottom. Mr. Justice Darling then sentenced Wiles to three months' imprisonment; Ross, who had been on bail, to eighteen months' imprisonment, without hard labour. The other two men, in considera. tion of their having been some time in prison, were sent to sixteen months' hard labour.-Daily Graphic, July 20th, 1904. 